\title{
Panorama global da distribuição e uso de água doce
}

Esta pesquisa refere-se a um estudo sobre o panorama global da distribuição e uso de água doce. A água é vital para os seres humanos. Projeções sobre o futuro indicam que o atual cenário de escassez de recursos hídricos pode se agravar e provocar consequências dramáticas para a própria sobrevivência da humanidade. Esta pesquisa refere-se a um estudo sobre o panorama global da distribuição e uso de água doce. Foram analisados os principais documentos publicados pela Organização das Nações Unidas e realizada revisão bibliográfica para identificar a localização e o volume das principais fontes renováveis de água doce no mundo, além de identificar quais atividades são responsáveis pela retirada e consumo de água doce. As atividades desenvolvidas em prol da agricultura, a indústria e a municipalidade são as que mais retiram e consomem água. Há ainda atividades como a produção de energia e os serviços prestados pelos ecossistemas que utilizam água, mas que em geral ou são computados pela indústria, no caso específico de produção e distribuição de energia, ou reciclam a própria água, como é o no caso dos ecossistemas. Existe outro fator de preocupação e que tem influenciado a distribuição das fontes renováveis de água doce no planeta que são as mudanças climáticas, que exercem grande influência no ciclo hidrológico ao não assegurar que as tendências hidrológicas passadas sejam referências para prever a disponibilidade futura de água. Os resultados apontam para a urgente necessidade de adotar ações sustentáveis no uso da água e a busca urgente e contínua de soluções para tornar seu uso eficiente com tecnologias que reduzam o seu consumo e consequentemente da retirada de água.

Palavras-chave: Distribuição da água doce; Uso da água; Gestão da Água; Eficiência.

\section{Overview of the global distribution and use of freshwater}

This research aim to study about the global picture of the distribution and use of freshwater. Water is vital for human beings. Projections on the future indicate that the current scenario of scarcity of freshwater resources may worsen and cause dramatic consequences for the mankind survival. This research refers to a study on the global distribution and use of freshwater and it was analyzed the main documents published by the United Nations and conducted a bibliographic review to identify the location and volume of renewable sources of freshwater in the world, and in addition it was identified what activities are responsible for the withdrawal and consumption of freshwater. The activities undertaken in favor of agriculture, industry and the municipality are the ones that most remove and consume water. There are also activities such as energy production and the services provided by ecosystems that use water, but which are generally computed by the industry, in the specific case of energy production and distribution, or recycle the water itself, as in the case of ecosystems. There is another factor of concern and that has influenced the distribution of renewable sources of freshwater on the planet that are climate change, which exert great influence on the hydrological cycle by not ensuring that hydrological trends reference to predict the future availability of water. The results point to the urgent need to adopt sustainable actions in the use of water and the urgent and continuous search for solutions to make their use efficient with technologies that reduce their consumption and consequently the withdrawal of water.

Keywords: Distribution of freshwater; Water use; Water management; Efficiency.

Topic: Desenvolvimento, Sustentabilidade e Meio Ambiente

Reviewed anonymously in the process of blind peer.
Received: 12/04/2019

Approved: 27/05/2019
Jefferson Fernandes do Amaral Silva (D) Universidade Federal Fluminense, Brasil http://lattes.cnpq.br/3839041385181293 http://orcid.org/0000-0002-3949-367X amaralifs@gmail.com

Roberto Guimarães Pereira (ic

Universidade Federal Fluminense, Brasil http://lattes.cnpq.br/9607255646013062 http://orcid.org/0000-0001-6094-1396 temrobe@vm.uff.br
Referencing this:

SILVA, J. F. A.; PEREIRA, R. G.. Panorama global da distribuição e uso de água doce. Revista Ibero Americana de Ciências Ambientais, v.10, n.3, p.263-280, 2019. DOI: http://doi.org/10.6008/CBPC2179$\underline{6858.2019 .003 .0023}$ 


\section{INTRODUÇÃO}

A água é imprescindível à vida. O ser humano a utiliza com diversos propósitos. Além de ser parte de suas necessidades fisiológicas básicas, é utilizada em atividades de lazer, na agricultura e na indústria. A água está distribuída na superfície da terra entre água doce e água salgada. Apenas 2,5\% se encontram na forma de água doce, cuja maior parte está em forma de gelo nas regiões do Ártico, da Antártica e das montanhas, aproximadamente $68,9 \%$, em águas subterrâneas, cerca de $29,9 \%$, e 0,9\% está em pântanos, permafrost e umidade do solo. Somente $0,3 \%$ está na superfície. E a presença na superfície da terra se fundamenta no ciclo hidrológico, cujo resultado é o escoamento de $42.700 \mathrm{Km}^{3} /$ ano de água pelos rios, distribuídos de forma irregular, gerando áreas de notável abundância como, por exemplo, a Amazônia e outras de elevado estresse hídrico como as regiões do norte da África e da Península Arábica.

O conhecimento da distribuição das fontes renováveis de água doce e sua relação com as demandas econômicas e sociais da humanidade é importante para superar os enormes desafios que se apresentam pela escassez desse recurso e pela ação antrópica, que mesmo em áreas de baixa vulnerabilidade tem causado a degradação de sua qualidade, fazendo com que recursos financeiros sejam demandados para restituir a qualidade da água que retorna para rios e demais corpos d'água. Além de conhecer como as fontes renováveis de água doce estão distribuídas na superfície do planeta, faz-se mister entender como a humanidade tem se utilizado desse recurso. Os principais setores que fazem uso da água incluem a agricultura, a indústria e a municipalidade, que se destina ao uso direto pela população.

O uso de água pela humanidade enfrenta um novo fator de preocupação: as mudanças climáticas. A principal ameaça decorre do fato de que as tendências hidrológicas passadas já não servem como referências para prever a disponibilidade futura de água. Além dos fatores naturais que interferem nas mudanças climáticas, a ação do homem tem contribuído para tal, em face do uso indiscriminado de combustíveis fósseis na geração de energia, na construção de reservatórios artificiais e de desvios de cursos d'água, assim como na ocupação de espaços, tanto para assentamentos urbanos como para a prática da agricultura, que aumentam sobremaneira a demanda por recursos hídricos.

Este artigo tem por objetivo explorar dados sobre a distribuição das fontes de água doce no mundo e o seu uso, apontando para a necessidade de torná-lo cada vez mais eficiente nas diversas atividades que a demandam, incluindo a redução do volume consumido, o tratamento dos efluentes e a preservação dos ecossistemas para assegurar à humanidade sua própria sobrevivência.

\section{METODOLOGIA}

Para avaliar o panorama da água no mundo foram considerados os principais relatórios emitidos pela Organização das Nações Unidas (ONU), incluindo relatórios da United Nation Water (UN Water), que é a agência de coordenação de mecanismos relacionados com questões sobre água doce e saneamento. 0 escopo do trabalho da agência UN Water engloba todos os aspectos da água doce, incluindo recursos de águas superficiais e subterrâneas e a interface entre a água doce e a água do mar. Entre os relatórios estão 
incluídos o World Water Development Report (WWDR), cuja coordenação é realizada pelo World Water Assessment Programme (WWAP), representando a agência UN Water e que é publicado anualmente.

Para avaliação das principais demandas de água pela humanidade recorreu-se ao sistema global de informações sobre água (AQUASTAT), que é mantido e atualizado pela Organização das Nações Unidas para Agricultura e Alimentação (Food and Agriculture Organization of the United Nations - FAO), assim como relatórios e estudos publicados pela Organização Mundial de Saúde, pelo United Nations Department of Economic and Social Affairs (Population Division), da Agência Internacional de Energia e do Intergovernmental Panel on Climate Change (IPCC).

\section{RESULTADOS}

Esta seção apresenta os principais resultados obtidos após a realização da revisão da literatura e está dividida da seguinte forma: água doce no mundo; distribuição das fontes renováveis de água doce; retirada e uso da água; variabilidade, vulnerabilidade e incerteza.

\section{A água doce no mundo}

A água predomina na superfície do Planeta Terra, cobrindo cerca de $70 \%$ do total. As terras emersas cobrem os $30 \%$ restantes. Shiklomanov (2000) afirma que a hidrosfera, camada do planeta que contém água, a possui nas três fases: líquida, sólida e gasosa. Está distribuída na atmosfera, na superfície da terra e internalizada na crosta terrestre até a profundidade de $2.000 \mathrm{~m}$. O volume de água da hidrosfera alcança $1.386 \times 10^{6} \mathrm{Km}^{3}$, mas só uma pequena parte, $2,5 \%$ do total, apresenta-se como água doce.

Do total de água doce, 68,9\% encontram-se na forma de gelo e coberturas de neve na Antártica, no Ártico e nas regiões montanhosas. Outros $29,9 \%$ encontram-se em águas subterrâneas e aquíferos e 0,9\% está em pântanos, permafrost e como umidade no solo. Somente $0,3 \%$ do volume total da água doce está disponível em lagos, reservatórios e bacias hidrográficas.

A presença da água no estado líquido nas terras emersas fundamenta-se no ciclo hidrológico global. Este ciclo se baseia na contínua troca de fases da água, onde fatores como a força dos ventos e o aquecimento proveniente da energia solar, que impulsionam o deslocamento de vapor de água para as terras emersas, e a força da gravidade causam a precipitação, a infiltração e o movimento de consideráveis massas de água (SHIKLOMANOV, 2000). A Figura 1 ilustra o ciclo hidrológico.

A evaporação, a precipitação, a transpiração da vegetação, a percolação, a infiltração e a drenagem constituem-se nos elementos principais do ciclo hidrológico. A cada ano, esse fenômeno movimenta 577.000 $\mathrm{km}^{3}$ de água. Este volume abrange a água que evapora da superfície dos oceanos $\left(502.800 \mathrm{~km}^{3}\right)$ e das terras emersas $\left(74.200 \mathrm{~km}^{3}\right)$. Todo este Volume é precipitado na superfície da terra, sendo que $458.000 \mathrm{~km}^{3}$ são lançados sobre os oceanos e $119.000 \mathrm{~km}^{3}$ sobre as terras emersas. A diferença entre a precipitação e a evaporação da água que ocorre nas terras emersas $\left(119.000-74.200=44.800 \mathrm{~km}^{3}\right)$ constitui-se no volume de água que escoa pelos rios $\left(42.700 \mathrm{~km}^{3} / \mathrm{ano}\right)$ e no volume menor $\left(2.100 \mathrm{~km}^{3} / \mathrm{ano}\right)$ de escoamento via águas subterrâneas, que segue direto para os oceanos. Esse é o volume das fontes renováveis de água doce, sobre 
o qual a humanidade busca garantir e produzir os diversos bens e atender as necessidades para a sua sobrevivência e bem-estar.

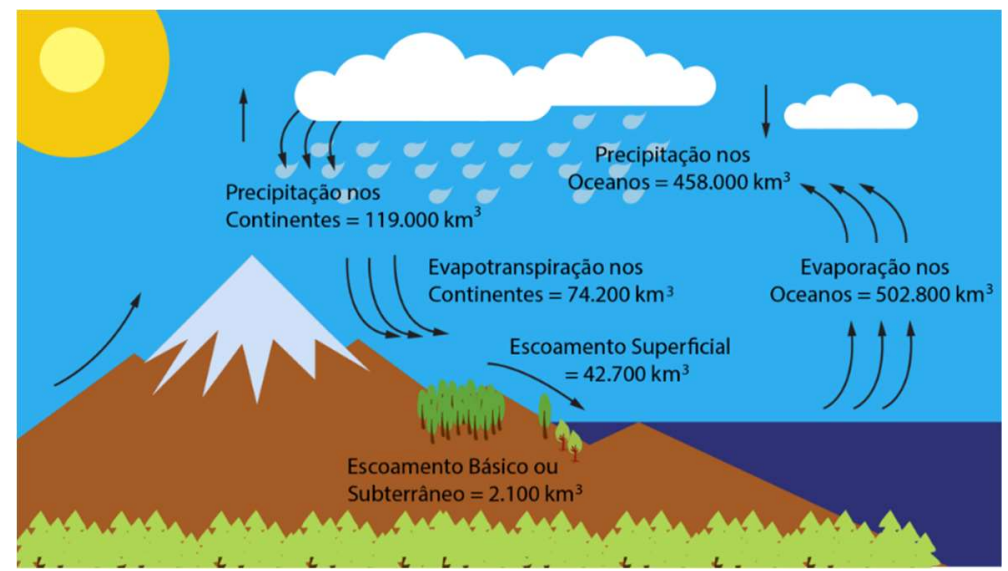

Figura 1: Ciclo hidrológico. Fonte: Adaptado de Shiklomanov (2000).

\section{Distribuição das fontes renováveis de água doce}

O Relatório WWAP The United Nations World Water Development Report 4: Managing Water under Uncertainty and Risk (Vol. 1), Knowledge Base (Vol. 2) and Facing the Challenges (Vol. 3), publicado em 2012 pelo United Nation Water (UN Water), cita que a precipitação geral ocorre de forma irregular sobre a superfície do planeta. Existe considerável variação entre climas áridos e úmidos e entre estações secas e chuvosas. Como resultado, a distribuição das fontes renováveis de água doce ocorre de forma irregular em diferentes países e regiões.

A Organização das Nações Unidas para Agricultura e Alimentação (Food and Agriculture Organization of the United Nations - FAO) mantém um sistema global de informações sobre água (AQUASTAT) para o qual são coletados, analisados e divulgados dados e informações, por países, sobre os recursos hídricos, uso de água e gestão dos recursos hídricos para a agricultura.

A FAO define fonte renovável de água doce como a vazão média anual de rios e a recarga de aquíferos, gerados a partir da precipitação. E define fontes não renováveis de água como os corpos de águas subterrâneas, aquíferos profundos, que têm uma taxa insignificante de recarga na escala de tempo humana e, portanto, podem ser considerados não renováveis. O total das fontes renováveis de água doce (Total Renewable Water Resources - TRWR) de um país é a soma das fontes internas renováveis de água doce (Internal Renewable Water Resources - IRWR) com as fontes externas renováveis de água doce (External Renewable Water Resources - ERWR). Esse total corresponde ao volume anual máximo teórico de água doce disponível para um país ao longo de um ano.

O sistema FAO - AQUASTAT concentra dados sobre a distribuição das fontes renováveis de água doce no planeta, cuja ilustração é apresentada na Figura 2. A Tabela 1 apresenta os dez países que possuem os maiores volumes totais de fontes renováveis de água doce do mundo, assim como o volume gerado internamente (IWRW). Também, apresenta os dez países com os menores volumes totais de fontes renováveis de água doce. 


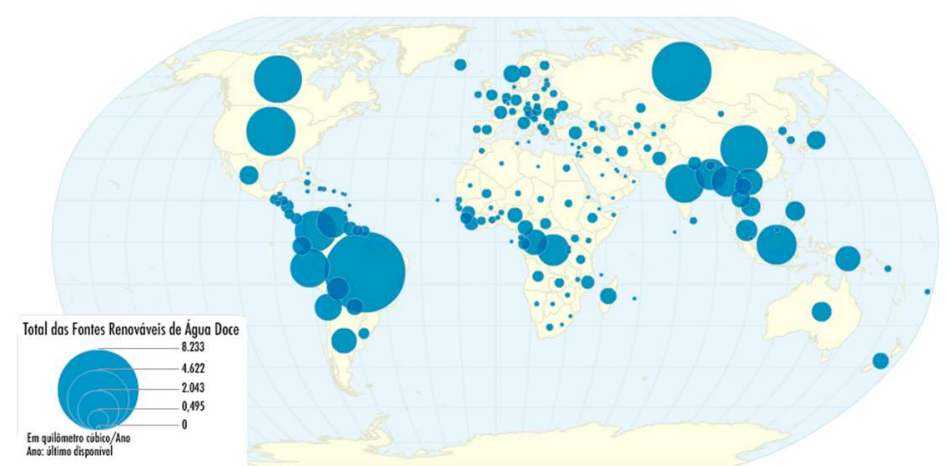

Figura 2: Média anual total das fontes renováveis de água doce por países. Fonte: FAO (2010).

Tabela 1: Países com maiores e menores volumes totais de fontes renováveis de água doce.

\begin{tabular}{|c|c|c|c|c|}
\hline \multicolumn{5}{|c|}{ Fontes renováveis de água doce } \\
\hline \multicolumn{3}{|l|}{ Maiores Volumes } & \multicolumn{2}{|l|}{ Menores Volumes } \\
\hline \multicolumn{3}{|l|}{$\mathrm{Km}^{3}$ ao ano } & \multicolumn{2}{|l|}{$\mathrm{Km}^{3}$ ao ano } \\
\hline País & Total (TWRW) & Interno (IWRW) & País & TWRW \\
\hline Brasil & 8.647 & 5.661 & Kuwait & 0,02 \\
\hline Rússia & 4.525 & 4.312 & São Cristovão e Neves & 0,024 \\
\hline Estados Unidos & 3.069 & 2.818 & Maldivas & 0,03 \\
\hline Canadá & 2.902 & 2.850 & Malta & 0,0505 \\
\hline China & 2.840 & 2.813 & Antígua e Barbuda & 0,052 \\
\hline Colômbia & 2.360 & 2.145 & Catar & 0,058 \\
\hline Indonésia & 2.019 & 2.019 & Barbados & 0,08 \\
\hline Índia & 1.911 & 1.446 & São Vicente e Grenadinas & 0,1 \\
\hline Peru & 1.880 & 1.641 & Bahrein & 0,116 \\
\hline Venezuela & 1.325 & 805 & Emirados Árabes & 0,15 \\
\hline
\end{tabular}

Fonte: FAO (2018).

A análise da Figura 2 e da Tabela 1 permite constatar que existem países com mais disponibilidade de água doce que outros. O Brasil concentra a maior fonte renovável de água doce do planeta, mesmo considerando somente suas fontes internas renováveis. No espectro de países com os menores volumes de fontes renováveis de água doce destacam-se os países do Golfo Pérsico e aqueles cujos territórios são ilhas localizadas no Mar do Caribe, Oceano Índico e Mar Mediterrâneo.

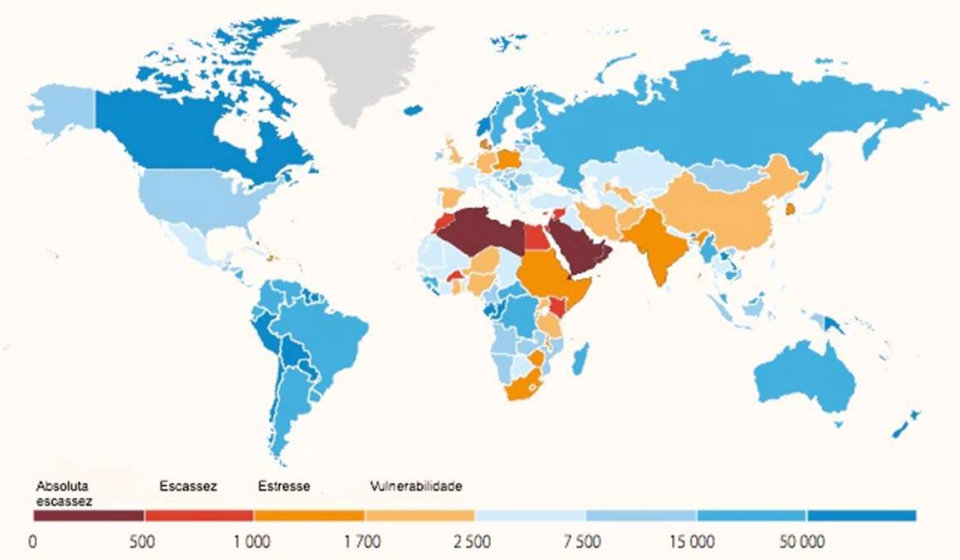

Figura 3: Média anual total das fontes renováveis de água doce em $\mathrm{m}^{3}$ por países per capita. Fonte: A partir de dados obtidos no FAO (2013) e WWAP (2014).

O Relatório 'WWAP (United Nations World Water Assessment Programme) The United Nations World Water Development Report 2014: Water and Energy', publicado pela UNESCO (United Nation Educational, Scientific and Cultural Organization) em 2014, considera que o total das fontes renováveis de 
água doce por habitante ilustra com mais realismo a relação da água com o ser humano, e contribui para uma melhor compreensão dessa distribuição ao longo da superfície do planeta, fornecendo uma indicação da disponibilidade de água tanto para fins econômicos como para fins sociais.

A Figura 3 ilustra a média anual total das fontes renováveis de água doce em metros cúbicos $\left(\mathrm{m}^{3}\right)$ por países per capita. A Tabela 2 apresenta os países com as maiores médias anuais totais das fontes renováveis de água doce em $\mathrm{m}^{3}$ per capita. Também, apresenta os países com as menores médias anuais totais das fontes renováveis de água doce em $\mathrm{m}^{3}$ per capita.

Tabela 2: Países com médias anuais totais das fontes renováveis de água doce em $\mathrm{m}^{3}$ per capita

\begin{tabular}{|l|l|l|l|}
\hline \multicolumn{2}{|l|}{ Fontes renováveis de água doce per capita } \\
\hline Maiores Médias/per capita & $\mathrm{m}^{3}$ ao ano/per capita & Menores Médias/per capita \\
\hline País & 516.090 & País & $\mathrm{m}^{3}$ ao ano/per capita \\
\hline Islândia & 353.279 & Kuwait & 5,139 \\
\hline Guiana & 182.320 & Emirados Árabes & 16,38 \\
\hline Suriname & Catar & 25,95 \\
\hline Congo & 180.087 & Arábia Saudita & 76,09 \\
\hline Papua Nova Guiné & 105.132 & lêmen & 78,26 \\
\hline Butão & 100.671 & Maldivas & 82,49 \\
\hline Gabão & 96.232 & Bahrein & 84,24 \\
\hline Canadá & 80.746 & Singapura & 107,1 \\
\hline Ilhas Salomão & 76.594 & Líbia & 111,5 \\
\hline Noruega & 75.417 & Malta & 120,6 \\
\hline
\end{tabular}

Fonte: FAO (2018).

A análise da Figura 3 e da Tabela 2 permite constatar que existem países com absoluta escassez de água no norte da África e na Península Arábica e outros sem qualquer tipo de vulnerabilidade como a Islândia e o Canadá. A Tabela 3 apresenta os países com maiores populações do mundo e suas respectivas médias anuais totais das fontes renováveis de água doce em $\mathrm{m}^{3}$ per capita.

Tabela 3: Países mais populosos e suas fontes renováveis de água doce per capita

\begin{tabular}{|l|l|l|}
\hline \multicolumn{2}{|l|}{ Países mais populosos e suas Fontes renováveis de água doce per capita } \\
\hline País & População (habitantes) & $\mathrm{m}^{3}$ ao ano/per capita \\
\hline China & 1.407 .306 .000 & 2.018 \\
\hline Índia & 1.311 .051 .000 & 1.458 \\
\hline Estados Unidos & 321.774 .000 & 9.538 \\
\hline Indonésia & 257.564 .000 & 7.839 \\
\hline Brasil & 207.848 .000 & 41.603 \\
\hline Paquistão & 188.925 .000 & 1.306 \\
\hline Nigéria & 182.202 .000 & 1.571 \\
\hline Bangladesh & 160.996 .000 & 7.621 \\
\hline Rússia & 143.457 .000 & 31.453 \\
\hline México & 127.017 .000 & 3.637 \\
\hline
\end{tabular}

Fonte: FAO (2018).

China, Índia, Paquistão e Nigéria apresentam volumes de água doce $\left(\mathrm{m}^{3}\right)$ per capita que os colocam em situação de vulnerabilidade, ao passo que Brasil e Rússia possuem abundância no volume das fontes renováveis de água doce per capita, cujos valores superam $30.000 \mathrm{~m}^{3}$ per capita.

\section{Retirada de água}

Segundo a FAO, cerca de $3.853 \mathrm{~km}^{3}$ de água doce são retirados anualmente das fontes renováveis por todos os países do mundo para suprir suas principais necessidades. Este volume corresponde a $9 \%$ do 
total interno das fontes renováveis de água doce (FAO, 2016). A tabela 4 apresenta os principais volumes de retirada de água doce por países, assim como o percentual dessas retiradas sobre o total das fontes renováveis de água doce. Também, apresenta os países com os maiores percentuais de retirada.

Tabela 4: Países com maiores volumes e percentuais de Retirada de Água sobre TWRW

\begin{tabular}{|l|l|l|l|l|}
\hline \multicolumn{2}{|l|}{ Volume de Retirada de Água e Percentual sobre TWRW } \\
\hline Maiores Volumes & Percentual sobre TWRW & \multicolumn{2}{l|}{ Maiores percentuais de retiradas } \\
\hline País & $\mathrm{Km}^{3}$ ao ano & $\%$ & País & $\%$ \\
\hline Índia & 647,5 & 33,88 & Kuwait & 2075,00 \\
\hline China & 594,2 & 21,12 & Emirados Árabes & 1867,00 \\
\hline Estados Unidos & 418,7 & 13,64 & Arábia Saudita & 943,30 \\
\hline Paquistão & 183,5 & 74,35 & Líbia & 822,90 \\
\hline Indonésia & 113,3 & 5,61 & Catar & 374,10 \\
\hline Irã & 93,1 & 67,96 & Bahrein & 205,80 \\
\hline México & 85,66 & 17,73 & lêmen & 168,60 \\
\hline Vietnam & 81,86 & 9,26 & Egito & 126,60 \\
\hline Filipinas & 81,56 & 17,03 & Turcomenistão & 112,50 \\
\hline Japão & 81,22 & 18,89 & Uzbequistão & 100,60 \\
\hline
\end{tabular}

Fonte: FAO (2018).

Os maiores volumes de retirada estão associados aos maiores contingentes populacionais. Todos os países citados na Tabela 4 com maiores volumes de retirada possuem contingentes populacionais superiores a 90 milhões de habitantes. Constata-se um elevado percentual de retirada em relação ao total das fontes renováveis de água doce para esses mesmos países. A exceção se dá com a Indonésia e com o Vietnam, que possuem elevados volumes totais (TWRW), respectivamente, $2019 \mathrm{Km}^{3}$ e $884,1 \mathrm{Km}^{3}$.

Por outro lado, existem países que retiram volumes superiores aos das suas fontes renováveis de água doce para atender suas demandas. É o caso dos países citados na Tabela 4, entre os quais estão Kuwait, que demanda mais de 20 vezes água doce em relação as suas fontes renováveis, Emirados Árabes, com uma demanda 18 vezes superior, e Arábia Saudita e Líbia com demandas de quase 10 vezes seus TWRW. As demandas desses países são supridas em sua maior parte por dessalinização e reuso, entre alternativas.

\section{Uso da água}

As principais atividades nas quais o homem utiliza a água com fins econômicos e sociais incluem a alimentação e higiene; produção industrial; geração de energia; irrigação; navegação; pesca e lazer; evacuação e diluição de esgotos; drenagem e controle de enchentes; combate a incêndios; preservação do ambiente aquático e da paisagem.

Segundo o WWAP (2012), a demanda por água pela humanidade engloba cinco grandes setores/atividades: a) Alimentação e agricultura, que são responsáveis pela maior retirada de volume de água do mundo; b) Energia, em que as quantidades de água utilizadas, consuntiva e não consuntiva, raramente são computadas e, portanto, são mal conhecidas; c) Indústria, que abrange uma ampla gama de atividades com impactos igualmente amplos, tanto na quantidade como na qualidade das fontes de recursos hídricos locais e no meio ambiente; d) Aglomerados humanos, que abrange a água utilizada para beber e para uso doméstico, incluindo tarefas como preparo de alimentos, limpeza, higiene e alguns aspectos do saneamento; e) Ecossistemas, em que a demanda por água é determinada pelas exigências de água para manter ou 
restaurar os serviços que a sociedade espera que os mesmos forneçam.

Segundo informações obtidas no FAO, o volume de retirada de água doce das fontes renováveis no mundo é de $3.853 \mathrm{Km}^{3}$ e está distribuído da seguinte forma: 69\% para agricultura, 19\% para indústria e $12 \%$ para a municipalidade. Wada et al. (2016), afirmam que o consumo global de água aumentou seis vezes nos últimos 100 anos e continua crescendo a uma taxa de cerca de $1 \%$ ao ano.

\section{Alimentação e Agricultura}

Segundo o WWAP (2012), a agricultura é a atividade que mais utiliza água, sendo responsável por cerca de $70 \%$ do total de retirada de água para suprir as demandas da humanidade. A sua utilização na irrigação e na produção de alimentos constitui-se no maior fator de pressão sobre as fontes renováveis de água doce.

Segundo estudos do United Nations Department of Economic and Social Affairs, Population Division, publicados em 2017 (UNDESA, 2017), a população mundial, que em meados de 2017 encontrava-se em cerca de 7,6 bilhões de pessoas, deverá crescer quase 1 bilhão e atingirá 8,5 bilhões em 2030 e deverá aumentar ainda mais em 2050, alcançando 9,7 bilhões. E mantidos os parâmetros analisados, o mundo terá uma população de aproximadamente 11,1 bilhões habitantes em 2100.

Alexandratos et al. (2012), com projeções semelhantes sobre o aumento da população mundial para 2030 e 2050, estimam que haverá um aumento na demanda por alimentos, exigindo um crescimento de cerca de 38\% da produção agrícola anual do mundo no período entre 2005/2007 e 2030, e 60\% entre 2005/2007 e 2050, representando um aumento de 47\% nos países em desenvolvimento e um aumento de 18\% nos países desenvolvidos até 2030, e de 77\% e 24\%, respectivamente, até 2050.

Além do crescimento populacional exercer pressões sobre o uso da terra e da água, o desenvolvimento econômico e a saúde individual têm alterado o padrão das dietas da população, mudando de uma dieta predominantemente à base de amido para uma dieta à base de carne e laticínios, o que requer ainda mais água.

Segundo Hoekstra et al. (2007), "para se produzir 1 kg de arroz são necessários 3.500 litros de água, para produzir $1 \mathrm{~kg}$ de carne utiliza-se cerca de 15.000 litros, enquanto para produzir uma xícara de café, são necessários 140 litros". Esta mudança no padrão das dietas é a principal causa sobre o aumento do consumo de água nos últimos 30 anos e é provável que continue sendo até a metade do século 21.

O WWAP (2014) cita que há outro fator de pressão sobre o consumo de água na agricultura: a demanda por produtos agrícolas para a produção de biocombustíveis. Esta demanda representa a maior parcela na busca de novos produtos oriundos da agricultura nas últimas décadas, e foi o fator determinante para que os preços das commodities atingissem seus picos no biênio 2007-2008. Como os biocombustíveis, também, necessitam de água para suas fases de transformação, o consumo de água na produção de biocombustíveis a partir de culturas irrigadas pode ser muito maior do que para os combustíveis fósseis. 


\section{Energia}

A Agência Internacional de Energia (International Energy Agency - IEA) estima que as retiradas totais de água do globo para produção de energia em 2014 alcançaram $398 \times 10^{9} \mathrm{~m}^{3}$, representando cerca de 10\% do total de retirada global, dos quais $48 \times 10^{9} \mathrm{~m}^{3}$ foram consumidos. As projeções indicam que em 2040, as retiradas manterão uma certa estabilidade, alcançando $403 \times 10^{9} \mathrm{~m}^{3}$, contrastando com o consumo que aumentará para $76 \times 10^{9} \mathrm{~m}^{3}$, representando um aumento de $58 \%$ (IEA, 2016).

O Relatório Energy Access Outlook 2017, From Poverty to Prosperity, elaborado pela Agência Internacional de Energia, indica que em 2016 mais de 1,1 x $10^{9}$ pessoas ainda não tinham acesso à eletricidade, sendo que a maioria estava localizada nos países em desenvolvimento da Ásia e da África Subsaariana. O mesmo relatório cita que aproximadamente $2,8 \times 10^{9}$ pessoas, $38 \%$ da população mundial e quase $50 \%$ da população dos países em desenvolvimento, dependiam do uso da biomassa sólida para cozinhar em fogões tradicionais. Em 25 países, principalmente na África Subsaariana, mais de 90\% das famílias dependiam de madeira, carvão vegetal e resíduos para cozinhar (IEA, 2017).

O WWAP (2014) cita que "a demanda mundial de energia deverá crescer em mais de um terço até 2035, com China, Índia e os países do Oriente Médio sendo responsáveis por cerca de 60\% desse aumento". Estima-se que a demanda por eletricidade cresça aproximadamente $70 \%$ até 2035 . Este crescimento ocorrerá quase que integralmente nos países que não integram a OCDE (Organização para a Cooperação e Desenvolvimento Económico), sendo que a Índia e a China responderão por mais da metade desse crescimento. Este crescimento na demanda por energia aumentará a pressão sobre as fontes renováveis de água doce, tendo como consequência a elevação da vazão de retirada.

O setor de energia utiliza a água em maior ou menor grau para a sua geração propriamente dita. $O$ WWAP (2012) cita que "água e energia estão intrinsecamente conectadas". Esta afirmação fundamenta-se no fato de que entre as várias fontes de energia e diferentes técnicas de geração de eletricidade, todas utilizam a água em vários processos de produção, que inclui a extração de matéria prima, resfriamento em processos térmicos, limpeza de material, cultivo de colheitas para biocombustíveis e movimentação de turbinas. Por outro lado, a utilização de energia permite que a água obtida das principais fontes esteja disponível para uso e consumo pelo ser humano, por meio de bombeamento, transporte, tratamento, dessalinização e irrigação.

O vínculo existente entre a água e a energia irá transcender o uso e o consumo da água a meras considerações quantitativas. A produção de energia, também, gera impactos na qualidade da água. A poluição térmica, química, radioativa ou biológica pode ter impactos diretos sobre os ecossistemas, afetando os recursos hídricos. E em locais onde as emissões não são suficientemente controladas, uma quantidade considerável de terras agrícolas pode ser afetada pela chuva ácida. Da mesma forma, onde a escassez de água obriga nações a usarem fontes não tradicionais de água, como por exemplo a dessalinização, as escolhas precisarão ser sensíveis aos impactos que a demanda de energia elétrica trará sobre as fontes de água e sobre o meio ambiente (WWAP, 2012). 
O aumento no consumo de água para a geração de energia será motivado pela construção de usinas mais eficientes, com sistemas de resfriamento mais avançados, que reduzem as retiradas de água, mas aumentam o consumo, e devido, também, à expansão da produção de biocombustíveis. Os impactos locais e regionais relacionados à produção de biocombustíveis podem ser substanciais, em face de se constituir num método de produção de combustível que utiliza água intensivamente (IEA, 2016).

\section{Indústria}

Segundo o relatório WWAP (2012):

A indústria usa relativamente pouca água em escala global e é uma atividade que requer um suprimento acessível, confiável e ambientalmente sustentável. Aproximadamente $20 \%$ das retiradas de água doce do mundo são utilizadas pela indústria, embora isto varie entre regiões e países.

O WWAP (2014) cita que, "os países mais desenvolvidos têm uma proporção muito maior das retiradas de água doce para a indústria do que os países menos desenvolvidos, onde a agricultura predomina". É o caso dos Estados Unidos da América em que a indústria é responsável pela retirada de 51\% do volume total das fontes renováveis de água doce, a agricultura por $36 \%$ e a municipalidade por $13 \%$. 0 Egito, que é um país essencialmente agrário, utiliza $86 \%$ do volume total de retirada das fontes renováveis de água doce para a agricultura, 2,5\% para a indústria e 11,5\% para a municipalidade (FAO, 2016). Para que a indústria tenha um funcionamento eficaz deve existir um abastecimento sustentável de água na quantidade certa, na qualidade certa, no lugar certo, na hora certa e ao preço certo (PAYNE, 2007).

A degradação da qualidade da água, que está associada ao abastecimento de água e às descargas de efluentes, pode afetar a indústria, restringindo a sua expansão. Nos casos de contaminação da água de superfície ou subterrânea, a indústria se depara com o aumento dos custos em face da necessidade de realizar tratamentos adicionais. Embora esta exigência represente um alerta à indústria para considerar com mais veemência o uso de água reciclada ou recuperada, o aumento dos custos no uso da água, provavelmente, pesará sobre as decisões quanto à localização das atividades industriais das empresas (WWAP, 2012).

Em geral, a indústria tem acesso à água por um preço relativamente baixo. Um cenário de escassez de água, no entanto, poderá resultar em impostos mais elevados e encargos adicionais com tratamento e descarga da água. Há um argumento para o estabelecimento de uma estrutura de preços diferentes para o uso de água industrial, isto é, exigir que a indústria pague mais por volume de água do que o público em geral. $\mathrm{O}$ argumento é que a alta dos custos relacionados à utilização de água na indústria promoveria, naturalmente, um aumento na eficiência da utilização de água, uma vez que a realidade econômica dos custos aumentaria o preço dos produtos associados (WWAP, 2012). A indústria vai se deparar cada vez mais competindo por recursos limitados de água pelo fato de haver aumento do consumo em todos os setores, particularmente na agricultura com suas necessidades substanciais de água. Assim, todos estes setores estão agora sujeitos a maior incerteza (WWAP, 2012). 


\section{Aglomerados Humanos}

A municipalidade, segundo a FAO - AQUASTAT, é definida como o setor que retira água, principalmente, para o uso direto pela população. Geralmente é calculada como o total de água retirada pela rede de distribuição pública. Pode incluir parte das indústrias e agricultura urbana, que é conectada à rede municipal.

A população mundial experimentará aumentos significativos nas próximas décadas, com estimativas de que em 2050 alcançará $9,8 \times 10^{9}$ pessoas e 11,2 x 109 em 2100 (UNDESA, 2017). Atualmente, mais da metade da população mundial, cerca de 55\%, vive nas cidades, e espera-se que esta proporção aumente rapidamente. Entre $2018\left(7,6 \times 10^{9}\right)$ e $2050\left(9,8 \times 10^{9}\right)$, estima-se que a população mundial aumentará em $2,2 \times 10^{9}$, enquanto a população urbana aumentará $2,5 \times 10^{9}$ (UNDESA, 2018).

Isso significa que áreas urbanas irão absorver todo o crescimento da população durante as próximas quatro décadas, enquanto a população rural vai começar a diminuir daqui a uma década. Este aumento ocorrerá em cidades localizadas em países em desenvolvimento, enquanto a população urbana dos países desenvolvidos não irá variar significativamente. A Figura 8 apresenta a projeção das diversas regiões quanto à distribuição da população rural e urbana por regiões mais e menos desenvolvidas entre 1950 e 2050.

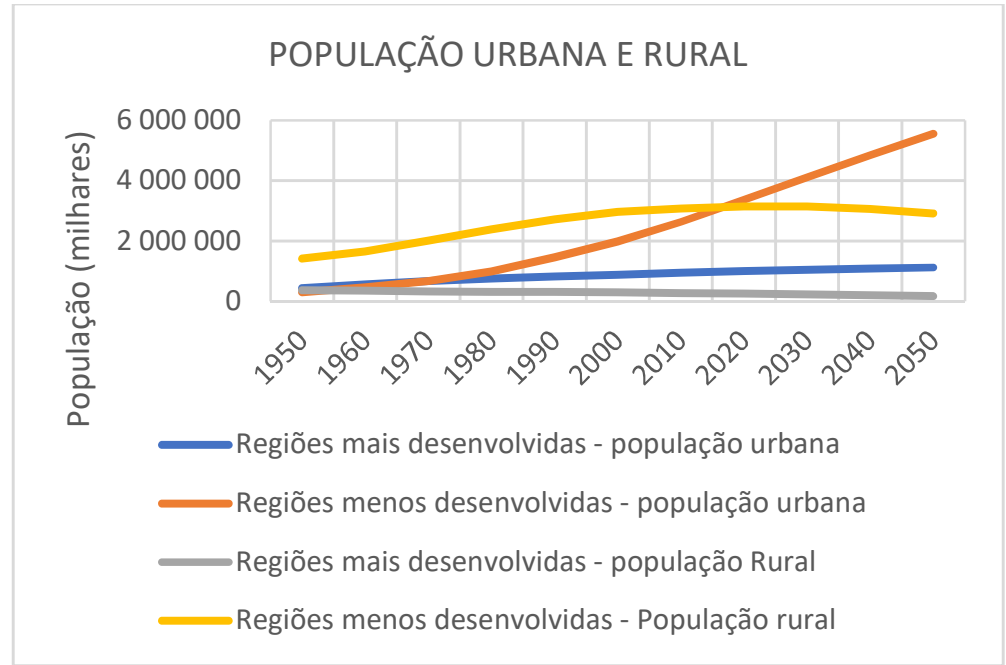

Figura 1: População rural e urbana por nível de desenvolvimento de países entre 1950 e 2050. Fonte: UNDESA (2018).

Há uma certa estabilidade nas populações urbana e rural nos países desenvolvidos, enquanto, nos países menos desenvolvidos as projeções indicam um aumento significativo das populações urbanas. Esta urbanização intensa que aumentará sobremaneira a demanda por serviços de saneamento, abastecimento de água e de eletricidade para fins domésticos. O WWAP (2012) cita que:

Cidades localizadas nos países em desenvolvimento enfrentam enormes carências em habitação, infraestrutura e serviços, assim como enfrentam insuficiente abastecimento de água, saneamento e aumento da poluição ambiental. $\mathrm{O}$ crescimento populacional e a rápida urbanização criarão uma demanda ainda maior por água, ao mesmo tempo em que ocorrerá uma diminuição da capacidade dos ecossistemas no abastecimento de água de forma regular e com a qualidade necessária.

Os conglomerados urbanos estão entre as principais causas de poluição das fontes renováveis de água doce. As águas residuais urbanas são particularmente ameaçadoras quando combinadas com resíduos 
industriais não tratados. Em muitas cidades, de pequeno e médio porte, com população inferior a 500.000 habitantes, que experimentam crescimento rápido, a infraestrutura de águas residuais é inexistente, insuficiente ou obsoleta.

Investir no abastecimento de água potável e nos sistemas de saneamento, promovendo a eficiência na prestação destes serviços, com subsídios para os mais pobres e proteger as fontes de água contra a poluição e a extração excessiva, são condições imperativas para garantir um acesso seguro à água para todos, particularmente para as populações urbanas mais pobres, que muitas vezes são relegadas a um segundo plano.

\section{Ecossistemas}

O WWAP (2014) cita que:

A disponibilidade de água em quantidades adequadas e com qualidade suficiente depende de ecossistemas preservados e este tipo de produto pode ser considerado um serviço prestado pelos mesmos. A manutenção dos fluxos ambientais provê este e outros serviços dos ecossistemas que são fundamentais para o crescimento econômico sustentável e o bem-estar do ser humano.

Os serviços proporcionados pelos ecossistemas, ou seja, para as populações, podem ser agrupados de várias formas. O Estudo do Milênio sobre Ecossistemas (MA, 2005) apresentou a avaliação mais abrangente sobre a situação global do meio ambiente. Entre os serviços provisionados pelos ecossistemas estão: a) Serviços de Suporte: são aqueles necessários para a produção de todos os demais serviços oferecidos pelos ecossistemas. Incluem a formação do solo, fotossíntese, produção primária, o ciclo dos nutrientes e o ciclo da água; b) Serviços de Suprimento: produtos obtidos do ecossistema, incluindo alimentos, fibras, combustíveis, recursos genéticos, bioquímicos, medicamentos naturais, produtos farmacêuticos, recursos ornamentais e água doce; c) Serviços de Regulação: são aqueles obtidos a partir da regulação dos processos do ecossistema, incluindo a regulação da qualidade do ar, regulação do clima, regulação da água, regulação da erosão, purificação da água, regulação de doenças, regulação de pragas, polinização e regulação dos perigos naturais, incluindo os extremos na disponibilidade de água; d) Serviços Culturais: os benefícios não materiais a serviço da população oferecidos pelo ecossistema através do enriquecimento espiritual, desenvolvimento cognitivo, reflexão, recreação e experiência estética, levando em consideração os valores da paisagem, incluindo a paisagem que possui água. O WWAP (2012) cita que:

Os ecossistemas, incluindo, por exemplo, florestas, pântanos e componentes de pastagem, estão no cerne do ciclo da água no globo. Toda a água doce, em última análise, depende do contínuo e saudável funcionamento dos ecossistemas, e reconhecer o ciclo da água como um processo da biofísica é essencial para alcançar uma gestão sustentável da água.

Historicamente, alguns têm considerado os ecossistemas como um usuário de água improdutivo. Isto é fundamentalmente incorreto, pois os ecossistemas não utilizam água, eles a reciclam. Mas as percepções estão mudando no sentido de gerenciar as interações humanas com ecossistemas, a fim de dar o suporte necessário aos objetivos de desenvolvimento relacionados com a água.

Todos os serviços do ecossistema terrestre, como produção de alimentos, regulação do clima, fertilidade do solo, armazenamento de carbono e reciclagem de nutrientes são sustentados pela água, assim 
como são, naturalmente, todos os serviços dos ecossistemas aquáticos. A disponibilidade de água e sua qualidade, em termos de uso direto por seres humanos, são, também, serviços prestados pelos ecossistemas, tanto quanto os benefícios que oferecem para atenuar os fenômenos extremos de seca e inundação.

\section{Variabilidade, vulnerabilidade e incerteza}

O WWAP (2014) cita que "um dos aspectos mais ameaçadores da mudança climática é o fato de que as tendências hidrológicas passadas já não são referências para prever a disponibilidade futura de água". De acordo com as projeções de clima mais recentes do Painel Intergovernamental sobre Mudanças Climáticas (Intergovernmental Panel on Climate Change - IPCC), as regiões secas, em larga escala, ficarão ainda mais secas e as regiões inundadas ficarão anda mais inundadas, e a variação geral aumentará (BATES et al., 2008).

As mudanças climáticas impactam o ciclo hidrológico e, consequentemente, os recursos hídricos. Seus efeitos representam um fator adicional de estresse e amplificam a já intensa competição sobre os recursos hídricos. Por exemplo, temperaturas mais altas e um aumento na taxa de evaporação podem afetar diretamente o abastecimento de água e potencialmente aumentar a demanda de água para a agricultura e para a produção de energia. Existem níveis significativos de incerteza com relação às projeções sobre mudanças do clima e essas incertezas aumentam muito quando o foco é direcionado para as escalas locais.

O WWAP (2012) cita que "os seres humanos estão interferindo no processo das mudanças climáticas que ocorrem no planeta e, por consequência, nos padrões globais de circulação da umidade". O controle sobre esta parte do ciclo hidrológico não é possível, mas os seres humanos têm um impacto significativo sobre outros componentes do ciclo. Algumas intervenções são deliberadas, tais como a modificação no curso natural do escoamento dos rios por meio de construção de reservatórios para armazenamento e de estruturas para permitir transferências entre bacias. Outras intervenções, tais como a alteração de áreas na superfície da terra para assentamentos urbanos ou para a agricultura, podem afetar severamente o ciclo hidrológico, pois interferem nas taxas de infiltração, escoamento superficial e evapotranspiração.

Segundo o WWAP (2012), o estado dos recursos hídricos está em constante mudança como resultado da variação natural do sistema de clima da Terra, da alteração decorrente da ação antrópica no próprio clima e na superfície do planeta, por meio do qual o ciclo hidrológico é modulado. As principais alterações nos recursos hídricos e no ciclo hidrológico incluem: a) Alterações nos principais fluxos de superfície devido à variação climática natural em escalas anuais e decenais, e às mudanças climáticas; b) Aumento potencial de inundações devido às mudanças climáticas; c) Aumento das perdas devido ao aumento de temperatura; d) Alterações na sazonalidade dos fluxos, especialmente nas bacias que dependem do derretimento de neve; e) Mudanças nos fluxos das geleiras devido ao recuo a que têm sido submetidas; f) Redução da neve e da camada de gelo que é misturada com o solo (permafrost); g) Esgotamento de águas subterrâneas, perdendo importante proteção contra variações da precipitação; h) Alterações na umidade do solo.

\section{DISCUSSÃO}

O ciclo hidrológico é o principal fator na distribuição das fontes renováveis de água doce no planeta, 
e se baseia em fenômenos como ventos, aquecimento solar, evaporação e precipitação, que movimentam e acumulam água sobre a superfície da terra em diferentes estados: líquido, sólido e gasoso. A configuração dos territórios dos países, como tamanho e posicionamento geográfico, tem relação direta com o volume de água doce que está disponível nos mesmos. Países com grandes dimensões territoriais possuem volumes expressivos de fontes renováveis de água doce. Rússia, Canadá, China, Estados Unidos e Brasil, que são os países com as maiores dimensões territoriais, possuem as maiores fontes renováveis de água doce do planeta.

É importante acrescentar que a localização geográfica é, também, um fator importante tanto sobre a distribuição como a precipitação. Há uma distribuição irregular nas diferentes regiões do planeta e são nas áreas tropicais, principalmente com vastas coberturas florestais, que ocorrem as maiores taxas de precipitação, contribuindo para que países como Brasil, Colômbia, Peru e Venezuela, estejam entre os que possuem volumes significativos de fontes renováveis de água doce. No cenário de escassez de fontes renováveis de água doce se encontram as regiões desérticas e países com pequenas extensões territoriais, como é o caso dos que são pequenas ilhas localizadas em diversos mares e oceanos. Enquadram-se nesses casos o Kuwait, Catar, Bahrein, Emirados Árabes, São Cristóvão e Neves, Maldivas, Malta, Barbados, Antígua e Barbuda e São Vicente e Granadinas.

Outro fator de relevância para a análise da distribuição das fontes renováveis de água doce é a relação entre os volumes disponíveis com a quantidade de habitantes existente em cada território. A relação volume de água per capita é a que melhor reflete a situação para efeitos sociais e econômicos. Os países mais populosos do mundo, como China e Índia, possuem relação, respectivamente, de 2.018 e $1.458 \mathrm{~m}^{3}$ ao ano/per capita que os colocam em situação de vulnerabilidade e estresse hídrico. Já países como Canadá e Noruega possuem uma relação de risco mínimo com valores, respectivamente, de $80.746 \mathrm{~m}^{3}$ e $75.417 \mathrm{~m}^{3}$ ao ano/per capita. Há absoluta escassez de água doce nos países localizados no norte da África e Península Arábica, cujas relações volume de fontes renováveis de água doce e número de habitantes fica abaixo de 100 $\mathrm{m}^{3}$ ao ano/per capita. Entre os países com absoluta escassez encontram-se Kuwait, Emirados Árabes, Catar, Arábia Saudita, lêmen, Bahrein, Singapura, Líbia e Malta.

A humanidade utiliza a água em diversas atividades para suprir suas necessidades e o faz por meio de retirada de água doce das fontes renováveis. Aproximadamente $3.853 \mathrm{~km}^{3}$ de água doce são retirados anualmente das fontes renováveis por todos os países do mundo para suprir suas principais necessidades. Este volume corresponde a $9 \%$ do total interno das fontes renováveis de água doce.

Os maiores volumes de retirada de água estão associados aos maiores contingentes populacionais. China, Índia e Estados Unidos retiram anualmente, respectivamente, volumes de $647,5 \mathrm{Km}^{3}, 594,2 \mathrm{Km}^{3} \mathrm{e}$ $418,7 \mathrm{Km}^{3}$. Entre os dez países com maiores volumes de retirada, todos possuem contingentes populacionais superiores a $90 \times 10^{6}$ habitantes. Constata-se um elevado percentual de retirada em relação ao total das fontes renováveis de água doce para esses mesmos países. A exceção se dá com a Indonésia e com o Vietnam, que possuem elevados volumes totais (TWRW), respectivamente, $2019 \mathrm{Km}^{3}$ e $884,1 \mathrm{Km}^{3}$.

Existem, também, países que retiram volumes superiores aos das suas fontes renováveis de água 
doce para atender suas demandas. Entre os quais estão Kuwait, que demanda mais de 20 vezes água doce em relação as suas fontes renováveis, Emirados Árabes, com uma demanda 18 vezes superior, e Arábia Saudita e Líbia com demandas de quase 10 vezes seus TWRW. As demandas desses países são supridas em sua maior parte por dessalinização e reuso, entre alternativas.

Embora o volume anual total de retirada de água doce das fontes renováveis no mundo, que atinge $9 \%$, represente um valor pequeno, existem regiões em que a retirada alcança entre 80 a $90 \%$, como é o caso das bacias hidrográficas de regiões áridas e semiáridas, onde a escassez predomina. Há países com cenário de escassez ainda mais dramático, que inclui países da Península Arábica, Ásia e norte da África. Em outras regiões, como as bacias hidrográficas tropicais, há uma grande quantidade de água doce disponível, mas sua distribuição irregular ao longo do tempo ocasiona o uso reduzido nos períodos de abundância ou exige a construção de infraestrutura visando proteger as pessoas nos períodos de escassez, por meio de armazenamento para uso posterior, com consideráveis impactos sociais e ambientais. Nas bacias hidrográficas localizadas em zonas temperadas os recursos hídricos são, de certa forma, uniformemente distribuídos ao longo do ano, mas são usados tão intensamente que poluem as fontes de água de superfície e subterrânea, ocasionando a escassez de água de boa qualidade.

O volume anual de retirada de água doce se destina a atender as principais demandas da humanidade, onde as atividades econômicas e sociais são as principais responsáveis pelo uso da água. Os setores de atividades mais representativos compreendem a Alimentação e Agricultura, Energia, Indústria, Aglomerados Humanos e os Ecossistemas.

A agricultura é a atividade que mais utiliza água. Cerca de $70 \%$ do volume de retirada de água doce é destinado à agricultura. As projeções de aumento da população do mundo, que deve alcançar 8,5 x $10^{9}$

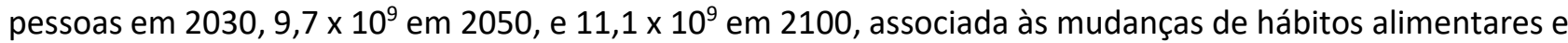
a procura intensa por produtos agrícolas para os biocombustíveis, indicam aumento sistemático e contínuo do consumo de água doce. Estes fatores irão aumentar a pressão sobre as principais fontes renováveis de água doce.

O aumento da população, o desenvolvimento econômico e a contínua busca da elevação no padrão de vida das populações irão aumentar a demanda por energia. Várias fontes de energia e diferentes técnicas de geração de eletricidade utilizam a água em vários processos de produção, que inclui a extração de matériaprima, resfriamento em processos térmicos, limpeza de material, cultivo de colheitas para biocombustíveis e movimentação de turbinas. A consequência direta é que a demanda maior por energia ocasionará uma demanda maior por água. Outro fator de pressão sobre o uso da água está relacionado com a demanda de energia para realizar o tratamento de água, cuja retirada ocorre, com cada vez mais frequência, em fontes com qualidade comprometidas, seja pela ação humana, poluindo os recursos hídricos, seja pela própria necessidade de produção de energia. Existe, ainda, nos cenários de escassez acentuada de fontes renováveis de água doce, a busca por fontes alternativas de água, que encontram na água salgada e na água salobra, fontes que demandam o uso intensivo de energia para torná-las utilizáveis pelo ser humano.

A indústria não consome tanta água como a agricultura, embora haja variações no consumo em face 
do nível de desenvolvimento de cada país. Os países mais desenvolvidos consomem volumes maiores de água na indústria do que os países menos desenvolvidos. $\mathrm{O}$ crescimento econômico e o desenvolvimento, que ao mesmo tempo exercem pressões sobre os recursos hídricos associados ao uso industrial, são sensíveis à disponibilidade desse insumo para assegurar a continuidade e o desenvolvimento da atividade econômica. Além da quantidade, a qualidade da água influencia os custos da indústria pela necessidade de tratamentos adicionais para que a água atenda aos requisitos que em determinadas ocasiões são até superiores aos parâmetros para consumo humano.

As projeções sobre a população mundial para as próximas décadas indicam um aumento significativo. Este aumento ocorrerá principalmente nos países menos desenvolvidos, sendo que a quase totalidade desse contingente ocupará espaços urbanos. Esse perfil de ocupação exigirá maiores retiradas de água doce para setores como agricultura, energia e indústria, e terá como consequência direta o aumento da demanda por recursos hídricos para serviços de saneamento, abastecimento de água e de eletricidade para fins domésticos. É exatamente nos conglomerados urbanos dos países menos desenvolvidos, que se concentram as principais fontes de poluição dos recursos hídricos, como consequência da falta de infraestrutura relacionada ao saneamento e ao tratamento de águas residuais. A maior demanda por água e a falta de serviços de saneamento e de tratamento de águas residuais compatíveis diminuirá a capacidade dos ecossistemas em prover água de forma regular e com a qualidade necessária.

Os ecossistemas não consomem água diretamente, mas preservá-los é essencial para assegurar o acesso à água doce em quantidades adequadas e com qualidade para o crescimento econômico sustentável e o bem-estar do ser humano. Os ecossistemas são provedores de serviços, tais como a produção de alimentos, regulação do clima, fertilidade do solo, armazenamento de carbono e reciclagem de nutrientes, serviços esses que são sustentados pela água.

As mudanças climáticas constituem-se no maior fator de incerteza quanto à disponibilidade dos recursos hídricos. A principal ameaça decorre do fato de que as tendências hidrológicas passadas já não servem como referências para prever a disponibilidade futura de água. Além dos fatores naturais que interferem nas mudanças climáticas, a ação do homem tem contribuído para tal, em face do uso indiscriminado de combustíveis fósseis na geração de energia, na construção de reservatórios artificiais e desvio de cursos d'água, assim como na ocupação de espaços tanto para assentamentos urbanos como para a prática da agricultura.

A demanda por água doce e energia continuará crescendo nas próximas décadas para atender às necessidades de crescimento das populações e das economias, concorrendo para mudar estilos de vida e causar evolução nos padrões de consumo, o que irá aumentar significativamente as pressões sobre recursos naturais limitados e sobre os ecossistemas. Os desafios resultantes serão mais agudos nos países em fase acelerada de transformação e rápido crescimento econômico e naqueles em que um grande segmento da população ainda não tem acesso a serviços mais modernos. As mudanças climáticas adicionam incerteza e ameaçam severamente qualquer projeção sobre a disponibilidade desses recursos para o atendimento das necessidades para o abastecimento das cidades no futuro. 


\section{CONCLUSÕES}

A água é essencial à vida, porém, este, essencial elemento, não está disponível de forma regular na superfície da Terra e exerce influência na qualidade de vida e no bem-estar das populações. A busca por fontes alternativas de água como a dessalinização representa importante alternativa para suprir as necessidades desses países e não limitar o seu desenvolvimento. Usar a água com eficiência será indispensável para assegurar o atendimento das principais demandas dessas populações.

O aumento da população, principalmente nos países menos desenvolvidos, é sem dúvida o maior problema a ser enfrentado. Este aumento tem consequência direta na retirada e no consumo de água doce das suas fontes renováveis. A necessidade de alimentar contingentes cada vez maiores de pessoas exige demandas crescentes de água para irrigação na agricultura, agravada pela mudança nos hábitos alimentares em que a sociedade, na busca por maior qualidade da alimentação, vem abandonando uma dieta predominantemente à base de amido para uma dieta à base de carne e laticínios, o que requer ainda mais água. A busca por combustíveis menos poluentes exerce pressões, também, na agricultura. A produção de biocombustíveis é uma realidade e demanda volumes expressivos de água para sua concretização.

A indústria consome água e o crescimento econômico dos países em desenvolvimento vem causando expressivo aumento das demandas por água. É um insumo importante e a qualidade da água exerce influência sobre a localização geográfica das unidades industriais que cada vez mais serão influenciadas pela disponibilidade desse importante insumo. Os aglomerados humanos representam outro desafio, pois o aumento da população do mundo nos próximos anos ocorrerá em países em desenvolvimento e tal aumento se dará essencialmente nas cidades, e aumentará a demanda por serviços de abastecimento e saneamento, além de provocar poluição das fontes.

É essencial manter os ecossistemas em plenas condições de prestar os seus serviços, que tem na reciclagem o seu maior benefício. A preservação dos ecossistemas é um enorme desafio e deve encampar as prioridades dos governos e da sociedade. Ecossistemas preservados significam água para suprir demandas da sociedade.

As mudanças climáticas exigem um planejamento adequado e ações coordenadas de todos para mitigar os efeitos nefastos que podem trazer sobre a humanidade. Estas fontes de mudança e as interações entre elas criam um nível de incerteza quanto ao uso e à disponibilidade de recursos hídricos, tornando-se ainda mais preocupante quando associadas às incertezas relacionadas ao clima da Terra e ao ciclo hidrológico.

O uso sustentável de água exige a busca urgente e contínua de soluções para tornar seu uso eficiente com tecnologias que reduzam o seu consumo e consequentemente da retirada de água, seja na agricultura, com técnicas de irrigação que evitem o desperdício e, também, a poluição dos lençóis freáticos/aquíferos, seja na indústria adotando processos de uso e tratamento de água eficientes ao mesmo tempo em que trata os efluentes para retorno aos corpos d'água. Passa, também, por métodos de produção de energia com tecnologias que reduzam o consumo e principalmente a retirada de água e por controle eficiente do consumo 
de água nos aglomerados urbanos que são os maiores poluidores, principalmente nos países menos desenvolvidos, onde a estrutura de saneamento e tratamento de esgoto é deficiente e polui as fontes de água doce. Outro e determinante aspecto no uso das fontes renováveis de água doce é a preservação dos ecossistemas, que são os garantidores da oferta de água, pois reciclam a água e tornam esse essencial elemento da natureza disponível para a própria preservação da espécie humana.

AGRADECIMENTOS: ao CNPq pelo apoio financeiro.

\section{REFERÊNCIAS}

ALEXANDRATOS, N.; BRUINSMA, J.. World agriculture towards 2030/2050: the 2012 revision. Rome: FAO, 2012.

BATES, B. C.; KUNDZEWICZ, Z. W.; WU, S.; PALUTIKOF, J. P.. Climate Change and Water. Technical Paper of the Intergovernmental Panel on Climate Change. Geneva: IPCC Secretariat, 2008.

FAO. Food and Agriculture Organization of the United Nations. AQUASTAT database. FAO, 2010.

FAO. Food and Agriculture Organization of the United Nations. AQUASTAT database. FAO, 2013.

FAO. Food and Agriculture Organization of the United Nations. AQUASTAT database. FAO, 2014.

FAO. Food and Agriculture Organization of the United Nations. AQUASTAT database. FAO, 2016.

FAO. Food and Agriculture Organization of the United Nations. AQUASTAT database. FAO, 2018.

HOEKSTRA, A. Y.; CHAPAGAIN, A. K.. Water footprints of nations: Water use by people as a function of their consumption pattern. Water Resource Manage, v.21, p.3548, 2007. DOI: http://doi.org/10.1007/s11269-006-9039-x

IEA. International Energy Agency. World Energy Outlook 2016. Paris: IEA, 2016.

IEA. International Energy Agency. Energy Access Outlook 2017. Paris: IEA, 2017.

MA. Millennium Ecosystem Assessment. Fresh water ecosystem services. Ecosystems and Human Well-being: Synthesis. Washington: Island Press, 2005.

PAYNE, J. G.. Matching water quality to use requirements. Technology Foresight Summit 2007. Water Productivity in Industry, 2007.

SHIKLOMANOV, I. A.. Appraisal and Assessment of World Water Resources. International Water Resources Association, v.25, n.1, p.11-32, 2000.

UNDESA. United Nations Department of Economic and Social Affairs, Population Division. World Population Prospects: The 2017 Revision, Key Findings and Advanced Tables. New York: UNDESA, 2017.

UNDESA. United Nations Department of Economic and Social Affairs, Population Division. World Urbanization Prospects: The 2018 Revision. New York: UNDESA, 2018.

WADA, Y.; FLORKE, M.; HANASAKI, N.; EISNER, S.; FISHER, G.; TRAMBEREND, S.; SATOH, Y.; VAN VLIET, M. T. H.; YILLIA, P.; RINGLER, C.; BUREK, P.; WIBERG, D.. Modeling Global Water Use for the 21st Century: the Water Futures and Solutions Initiative and Its Approaches. Geoscientific Model Development, v.9, p.175-222, 2016. DOI: http://doi.org/10.5194/gmd-9-175-2016

WWAP. World Water Assessment Programme. The United Nations World Water Development Report 4: Managing Water under Uncertainty and Risk. Paris: UNESCO, 2012.

WWAP. World Water Assessment Programme. The United Nations World Water Development Report 2014: Water and Energy. Paris: UNESCO, 2014.

A CBPC - Companhia Brasileira de Produção Científica (CNPJ: 11.221.422/0001-03) detém os direitos materiais desta publicação. Os direitos referem-se à publicação do trabalho em qualquer parte do mundo, incluindo os direitos às renovações, expansões e disseminações da contribuição, bem como outros direitos subsidiários. Todos os trabalhos publicados eletronicamente poderão posteriormente ser publicados em coletâneas impressas sob coordenação da Sustenere Publishing, da Companhia Brasileira de Produção Científica e seus parceiros autorizados. Os (as) autores (as) preservam os direitos autorais, mas não têm permissão para a publicação da contribuição em outro meio, impresso ou digital, em português ou em tradução. 